\title{
O uso de indicadores para avaliação qualitativa de projetos educativos socioambientais: a gestão participativa no ambiente escolar
}

\author{
Renato de Oliveira Brito ${ }^{a}$ \\ Luíz Siveres ${ }^{b}$ \\ Célio da Cunha ${ }^{c}$
}

\section{Resumo}

Este artigo tem como objetivo, discutir os novos paradigmas educacionais, voltados para o desenvolvimento sustentável, a fim de se construir um novo modelo de escola, a partir da interação mais eficaz de todos os envolvidos no processo educacional, das famílias dos alunos e da sociedade. Tal ideia se baseia no pressuposto da gestão participativa, e vai ao encontro da promoção da sustentabilidade no ambiente escolar ao se considerar que essa iniciativa envolve ações individuais, mas também coletivas. A educação ambiental não pode se reduzir a uma atuação focada apenas no indivíduo, de maneira fragmentada. Tampouco, pode se voltar para coletivos genéricos, abstratos, fora do contexto territorial e histórico. Este artigo visa, ainda, a discussão da efetividade do uso de indicadores qualitativos, no sentido de verificar se eles podem ser utilizados enquanto balizadores das políticas públicas voltadas à escola, bem como discutir a efetividade da gestão participativa na constituição de escolas sustentáveis.

Palavras-chave: Escolas sustentáveis. Desenvolvimento socioambiental. Paradigmas educacionais. Gestão participativa.

\section{Introdução}

A educação é antiga, tal qual a capacidade do ser humano em aprender. Surgiu como demanda nas diversas civilizações, mas no que se refere às escolas, como concebidas atualmente, elas constituem uma invenção relativamente recente na

\footnotetext{
a Universidade Católica de Brasília, Brasília, DF, Brasil.

b Universidade Católica de Brasília, Brasília, DF, Brasil.

c Universidade Católica de Brasília, Brasília, DF, Brasil.
} 
história. A escola tornou-se uma das instituições responsáveis pela transmissão de conhecimentos e de elementos culturais particulares ou que transformam dada sociedade. Diversas são as maneiras pelas quais os processos educativos têm se concretizado, mas é importante considerar que a tradição de aprender uns com os outros, e de transmitir conhecimentos acumulados ao longo de gerações, sempre esteve presente em qualquer cultura e grupo social (BORGES, 2011).

Os avanços tecnológicos, sociais e culturais das últimas décadas trouxeram uma mudança acentuada no processo de criação e implementação de políticas educacionais, isso porque os avanços tecnológicos mudaram, de maneira sem precedente, a forma e a rapidez do processo de troca de informação. Ao mesmo tempo, o mercado e a sociedade passaram a exigir indivíduos cada vez mais capacitados com as novas formas de ação e interação tecnológicas. Os indivíduos estão cada vez mais informatizados e as trocas de informações são feitas quase instantaneamente.

Desde a década de 1960, acontecem debates promovidos para pensar o meio natural e a qualidade do habitat humano. A partir de então, derivou-se uma preocupação com a qualidade ambiental a ser experimentada pelas gerações futuras, assim como com as atitudes necessárias para a preservação da natureza e de seus recursos. O ambiente escolar também foi impactado pelas discussões ambientais, inclusive via políticas públicas, que asseguraram a presença da educação ambiental para o desenvolvimento sustentável nas escolas.

Em função do seu papel no desenvolvimento social, a escola também deve assumir uma posição mais efetiva na luta pelo meio ambiente. Diante da premissa de constituir um espaço mais participativo, e que acumule funções sociais, não se admite mais uma forma única de organização ou de aprendizagem. A gestão participativa vai ao encontro da ressignificação desse espaço de formação.

Este artigo visa a evidenciar a efetividade do uso de indicadores qualitativos para mensurar os impactos das políticas públicas no ambiente escolar, numa avaliação realizada a partir do estudo de caso de Brito (2016), no qual foram analisadas quatro escolas com projetos ambientais, financiados via política pública, do Município de Sobral, no Ceará.

A partir desse caso, o artigo visa a contribuir para a compreensão de como a escola se comporta frente a seus novos paradigmas educacionais voltados para o desenvolvimento sustentável, a fim de se construir um novo modelo de escola, produzido a partir das novas tecnologias disponíveis, mas também pela interação 
mais eficaz de todos os envolvidos no processo educacional, das famílias e da sociedade. Trata-se de discutir a efetividade da gestão participativa na constituição de escolas sustentáveis.

\section{Questões ambientais e desenvolvimento sustentável: o papel transformador da educação}

A década de 1960 marcou o início de uma série de convenções e debates internacionais promovidos para pensar o meio natural, a qualidade do habitat humano, além de um modelo de desenvolvimento econômico que considerasse também dimensões sociais e ambientais. O Clube de Roma, em 1968, foi o pioneiro na discussão sobre a possibilidade de esgotamento dos recursos naturais e a irreversibilidade desse processo.

Em 1972, foi realizada pela Organização das Nações Unidas (ONU), a Conferência Mundial de Estocolmo sobre o Meio Ambiente Humano. Dentre as conclusões, o papel da educação foi valorizado para a disseminação e o trabalho sobre as questões referentes ao meio ambiente (UNESCO, 2005).

A Conferência Internacional sobre Educação Ambiental, promovida pela ONU no anod de 1977, realizada em Tbilisi, Geórgia, assinalou um conceito de meio ambiente que englobava uma série de elementos naturais e sociais, de modo que constituem um conjunto de valores culturais, morais e individuais, assim como as relações interpessoais na esfera do trabalho e das atividades de tempo livre.

O ano de 1987 foi marcado pela elaboração do Relatório de Brundtland, resultado das reuniões da Comissão Mundial sobre o Meio Ambiente e o Desenvolvimento, que popularizou a ideia de desenvolvimento sustentável enquanto meta para um aproveitamento equilibrado dos recursos naturais e enquanto modelo de convivência entre o homem e a natureza. Sua ideia pressupõe a existência de um modelo econômico, político, social, cultural e ambiental equilibrados, que satisfaça as necessidades das gerações atuais, sem comprometer as das gerações futuras (CATALISA, 2015).

Os documentos "A Carta da Terra" e a "Agenda 21" estão associados à Conferência das Nações Unidas sobre o Meio Ambiente e o Desenvolvimento (ECO-92), ocorrida no Rio de Janeiro, evidenciando o envolvimento brasileiro nos debates internacionais. Segundo Gadotti (2008), o primeiro tem um potencial educativo muito grande, uma vez que atribui à educação a responsabilidade de construção da viabilidade do desenvolvimento sustentável. 
Síveres (2010) reconhece o papel da educação, no sentido de que ela possibilita a construção da igualdade de acesso a oportunidades de qualidade de vida e na formação de uma consciência socioambiental, entretanto, afirma que a educação, sozinha, não é capaz de promover o desenvolvimento sustentável.

Com a evidente importância da educação no desenvolvimento sustentável, a educação ambiental passou a estar presente em uma série de políticas públicas nacionais. Foi abordada na criação da Política Nacional de Meio Ambiente (BRASIL, 1981), após anos de lutas dos ambientalistas, apesar de a lei não se caracterizar como uma política pública exclusiva para a questão. A Constituição Federal de 1988 (BRASIL, 1988) atribuiu ao Estado um papel de condutor da educação ambiental e facilitou a disseminação dessa atribuição aos órgãos e às instituições federais, estaduais, distritais e municipais.

A Política Nacional de Educação Ambiental foi instituída pela promulgação da Lei no 9.795/99 (BRASIL, 1999) e o Programa Nacional de Educação Ambiental - PRONEA (BRASIL, 2005) passou a ser desenvolvido pelo governo federal em 2005. Outros tratados e documentos foram promulgados no sentido de nortear a política e o programa citado, de modo que o Estado brasileiro estaria cada vez mais instrumentalizado para promover a educação ambiental (BARCHI, 2016).

Ao estudar a educação ambiental, Rucheinsky et al. (2012) destacam a sua natureza complexa, interdisciplinar e de forte potencial emancipatório. A implementação de um projeto bem-sucedido de educação ambiental envolve as dimensões de autonomia, descentralização, diversidade e comunidade, pois os conceitos de ambiente e de sociedade são indissociáveis.

Dada a importância da relação entre educação e desenvolvimento sustentável, a Década da Educação para o Desenvolvimento Sustentável (2005-2014) foi instituída em 2002, pela ONU. A ideia foi desenvolver estudos e projetos que pudessem dar forma a metodologias e práticas de educação formal e informal ambientalmente conscientes (UNESCO, 2005).

A Década da Educação constituiu-se em um conjunto de parcerias que procurou reunir uma grande diversidade de interesses e preocupações. Foi um instrumento de mobilização, difusão e informação, de modo que formou uma rede de responsabilidades, rede pela qual os governos, organizações internacionais, sociedade civil, setor privado e comunidades locais, ao redor do mundo, pudessem demonstrar seu compromisso prático de aprender a viver sustentavelmente (UNESCO, 2005). 
De acordo com a Unesco (2005), a educação para o desenvolvimento sustentável deve ser considerada uma abordagem de aprendizagem contínua. Tal afirmação abre espaço para a inferência de que os mais diversos atores sociais pertencentes à comunidade e às instituições, públicas e privadas, devem colaborar continuamente no processo de interação com a escola.

A educação ambiental surge como uma ferramenta importante para a construção de modelos racionais de produção, que possam promover o desenvolvimento sustentável. Considera-se que deve ser promovida sob um modelo pedagógico e metodológico de interdisciplinaridade, pois o que se percebe é que:

Segundo Leff (2001), para que a educação ambiental seja o elemento condutor do processo de transição para uma sociedade sustentável, é necessário unir educação e ética ambiental na construção de um modelo em que os princípios e valores ambientais, promovidos por uma pedagogia de complexidade, levem o educando a perceber as relações existentes entre o seu próprio desenvolvimento e a realidade do meio social, econômico e ambiental que o cercam, o que confere um caráter intersubjetivo ao saber.

A educação para o desenvolvimento sustentável não deve ser, necessariamente, equiparada à educação ambiental. Em algumas situações, a educação ambiental pode ser vista apenas como uma disciplina curricular, enquanto que a educação para o desenvolvimento sustentável possui um domínio mais amplo: abrange a educação formal e a informal, bem como um projeto de educação continuada. A educação ambiental é desafiadora e contribui fortemente para o desenvolvimento sustentável, pois, quando bem estruturada, enfatiza a relação dos homens com o ambiente natural, as formas de conservá-lo, preservá-lo e de administrar seus recursos adequadamente (UNESCO, 2005).

No ano de 2015, foram definidos 17 Objetivos de Desenvolvimento Sustentável (ODS), fixados pela ONU, que reuniu os líderes mundiais para adotar uma agenda audaciosa, com a finalidade de erradicar a pobreza e promover o desenvolvimento econômico, social e ambiental à escala global até 2030, a Agenda 2030 para o Desenvolvimento Sustentável.

A Agenda 2030 é produto de um trabalho conjunto de governos e cidadãos de todo o mundo para instituir um novo modelo global para romper com a pobreza, promover a prosperidade e o bem-estar de todos, resguardar o ambiente e combater as alterações climáticas, e agrega 17 ODS, sucessores dos 8 Objetivos de Desenvolvimento do Milênio. 
A Declaração de Incheon foi aprovada em 21 de maio de 2015, no Fórum Mundial de Educação (UNESCO, 2015), ocorrido na Coreia do Sul. A Declaração estabelece o compromisso da comunidade educacional com a Educação 2030 e a Agenda de Desenvolvimento Sustentável 2030 e, do mesmo modo, reconhece o importante papel da educação como principal motor do desenvolvimento.

O Marco de Ação da Educação 2030, que oferece orientações para implementação da Educação 2030, foi debatido EM 2015 no Fórum Mundial de Educação e seus elementos fundamentais foram acordados na Declaração de Incheon. Ele foi finalizado pelo Grupo Redator para o Marco de Ação da Educação 2030 e adotado por 184 Estados-membros e pela comunidade educacional, durante um encontro de alto-nível na Unesco, em Paris, em 2015.

O Marco de Ação visa a mobilizar todos os países e parceiros em torno dos ODS sobre educação e suas metas, além de propor formas de implementar, coordenar, financiar e monitorar a Educação 2030, a fim de garantir oportunidades de educação de qualidade inclusiva e equitativa, assim como aprendizagem ao longo da vida para todos. Propõe, ainda, estratégias indicativas, nas quais os países possam se basear para desenvolver planos e estratégias contextualizadas, que levem em consideração realidades nacionais, capacidades e níveis de desenvolvimento diferentes e respeitem as políticas e as prioridades nacionais.

\section{A gestão participativa e a promoção das escolas sustentáveis}

O desenvolvimento sustentável exige a implementação de inovações nos sistemas e processos educativos e de ensino-aprendizagem (NEWTON et al., 2011). $\mathrm{O}$ desafio reside no fato de que a escola ainda se utiliza, preponderantemente, dos mesmos métodos de ensino-aprendizagem e de valores. A gestão escolar está no cerne de toda essa discussão, no sentido de que cabe a ela a responsabilidade de buscar meios de desenvolver e programar, com o auxílio da comunidade escolar, a transformação ou a adaptação do processo administrativo-pedagógico para conduzir a escola à aquisição das funcionalidades que lhe são exigidas.

Se a escola surgiu para atender às necessidades de ensino e de aprendizagem de certo modelo de organização social, é fundamental que ela esteja sempre atenta e disposta a adaptar-se às mudanças, inclusive na maneira de os seres humanos interagirem entre si e com o meio em que habitam (BORGES, 2011).

A educação para a sustentabilidade é uma das novas demandas para o ensino, ao considerar que formar, no aluno, postura e comportamento conscientes para 
a construção e a manutenção de uma sociedade sustentável passa a ser também uma de suas atribuições. $\mathrm{O}$ centro desse processo, na escola, tem como atores principais os profissionais de educação, que devem exercer a prática sustentável e fazer com que a comunidade escolar e os alunos também desenvolvam um perfil alinhado com a proposta em questão.

Entender a educação como um processo contínuo de aprendizagem, de ação e de reflexão que envolve os atores individuais e coletivos, nos leva a considerá-la como força criadora de novas maneiras de pensar, refletir e agir. Transformar a ideia abstrata de desenvolvimento sustentável em realidade geral aos povos da terra é um desafio enorme, que tem, como centro, a educação, pois somente ela é capaz de efetuar essa transição (NEWTON et al., 2011).

O social e o ambiental podem caminhar juntos, além de influenciarem-se e determinarem-se mutuamente. Por isso, é preferível afirmar que os desafios enfrentados contemporaneamente não são apenas ambientais, mas socioambientais. Dizem respeito ao impacto provocado no ambiente natural pelas sociedades humanas em sua trajetória histórica que, por sua vez, incorre sobre a qualidade da própria vida humana no planeta.

No que se refere à gestão escolar no Brasil, a gestão participativa ou democrática foi gradualmente tomada como referência. $\mathrm{O}$ último termo foi expresso no art. 206 da Constituição Federal de 1988 (BRASIL, 1988), no sentido de evidenciar a importância e possibilitar uma participação mais ativa da comunidade e da família no cotidiano escolar (REZENDE; SILVA, 2016).

Como a gestão participativa, a governança também é um conceito ligado à dimensão democrática da ligação entre as políticas públicas e as instituições.

[...] o bom governo depende em grande medida das qualidades e compromissos dos governantes, mas depende, sobretudo, da capacidade de escolha, participação e controle da sociedade civil. Isto, obviamente, está diretamente relacionado com os níveis de 'empoderamento' (empowerment) de uma dada sociedade, o que por sua vez depende dos níveis de capital humano e capital social (PAULA, 2000, p. 62).

A partir da participação mais intensa dos agentes envolvidos no processo educacional, considera-se o pensamento de Novicki (2009, p. 224), que defende que a educação para o desenvolvimento sustentável deveria possuir as seguintes características: ser interdisciplinar e holística, ser parte integrante do currículo 
como um todo, não como uma matéria separada; favorecer o pensamento crítico e a solução de problemas; recorrer a múltiplos métodos; favorecer a participação dos alunos no processo de tomada de decisões; integrar ao cotidiano as experiências de aprendizagem oferecidas e ser localmente relevante: tratar as questões locais, assim como as globais, com uso de uma linguagem universal.

Sob essas orientações, a educação ambiental poderia promover a conscientização, o respeito ao meio ambiente e a criação de ações que possam ser repassadas e aceitas socialmente. Cabe ao professor, enquanto liderança no universo escolar, propiciar uma compreensão básica sobre o meio ambiente, principalmente quanto às influências do ser humano e de suas atividades, bem como suas responsabilidades com relação a ele e o que pode ser feito de positivo ou negativo.

É preciso que as escolas se identifiquem com os ideais sustentáveis e compreendam a importância de transformar suas atitudes e seus objetivos de ensino e aprendizagem. $\mathrm{O}$ ambiente escolar tem a capacidade de se comportar como um centro de referência sobre sustentabilidade para os alunos e para a própria comunidade que a envolve (BORGES, 2011).

A mudança de comportamento em relação à educação ambiental se dará de forma gradativa, uma vez que é necessário propiciar a aquisição de valores e motivar os envolvidos a participarem de forma ativa para o desenvolvimento do projeto de desenvolvimento sustentável. Essa competência será desenvolvida a partir do momento em que forem propiciadas condições aos alunos, e demais membros participantes, de adquirirem as habilidades necessárias a uma participação ativa.

Nessa mesma linha, Padilha (2003, p. 85) apresenta uma contribuição significativa:

O envolvimento com satisfação, num projeto qualquer, e, principalmente, no projeto político-pedagógico de uma escola depende da criação de vários espaços e tempos para que ele aconteça, espaços e tempos para encontros, festas, reuniões, confraternizações, passeios, estudo etc., e do estabelecimento de relações democráticas, de confiança e de comprometimento com um planejamento que vai se realizando, e com o projeto que se pretende construir.

A base de organização da gestão da educação e da escola não será hierarquizada, mas adotará um desenho circular que pressupõe a relação entre os atores sociais e uma partilha de poder, no exercício da corresponsabilidade nas ações da escola. A educação ambiental oferece respostas não apenas voltadas para os resultados, 
mas para o processo de aprendizagem, onde reside a raiz de uma revolução de hábitos e costumes em favor de um viver mais sustentável.

Os espaços educadores, dispostos a atuar na construção de uma nova cultura de sustentabilidade, podem valer-se dessas práticas e princípios, e empregá-los de maneira transversal, integral e interdisciplinar. Tornam-se, assim, espaços educadores sustentáveis, ou seja, espaços que têm a intencionalidade pedagógica de se constituírem em referências de sustentabilidade socioambiental.

Para Moreira (2011), a decisão de trilhar o caminho da sustentabilidade pressupõe a existência de instâncias de poder na escola que sejam capazes de empreender iniciativas para torná-la, gradualmente, mais sustentável e estimular a adoção de uma cultura que suporte as decisões tomadas.

O desafio de uma educação voltada para a sustentabilidade deve estar na construção constante de novas possibilidade e reflexões que promovam o aprendizado, o respeito às diversas formas de vida e ao planeta, e a perspectiva de poder construir um espaço culturalmente diverso, social e ecologicamente viável melhor para todos.

\section{Resultados}

A seleção de indicadores para avaliação necessita ser organizado em função dos aspectos que se almeja mensurar, como a eficácia, a eficiência ou a efetividade de uma determinada política pública. A eficiência refere-se ao bom emprego de recursos financeiros, materiais e humanos, em relação às atividades e resultados obtidos. A eficácia é a relação entre as ações efetivadas e os resultados alcançados. Já a efetividade é a observação da inclusão das transformações provocadas por verificado programa na realidade da população-alvo.

O processo de demarcação de indicadores é complexo, não somente porque reduz a noção de qualidade que se está adotando como referência para avaliação, como também por dificuldades de operacionalização, sobretudo, quando se trata de pesquisar objetos diversificados, geralmente focados na pesquisa social, domínio em que se implantam as iniciativas em educação.

As questões ambientais são, diretamente ou não, responsabilidade de todos os cidadãos. Enquanto entidade social, a escola promove meios para trabalhar a consciência ambiental junto a seus integrantes. Além da responsabilização individual, a responsabilidade ambiental atinge também o Estado. Nesse sentido, ele também precisa se engajar quanto aos problemas apresentados e, no que diz 
respeito ao ambiente escolar, já existem políticas públicas voltadas ao trabalho da construção da consciência ambiental e das escolas sustentáveis.

O Estado brasileiro promove ações no sentido de atender às questões que concernem o desenvolvimento sustentável. Evidência disso é o Programa Dinheiro Direto na Escola (PDDE) - Escolas Sustentáveis, que tem por objetivo destinar recursos financeiros a escolas públicas, a fim de promover a sustentabilidade socioambiental, apoiar as instituições no processo de implementação das Diretrizes Curriculares Nacionais para a Educação Ambiental e fomentar ações que as permitam se tornar espaços educadores sustentáveis.

[...] o princípio fundamental da política para Escolas Sustentáveis é que as escolas de educação básica brasileira se transformem em "incubadoras de mudanças", onde deverão encontrar possíveis soluções para as dificuldades encontradas. A proposta busca, a partir de espaços educadores sustentáveis, incentivar a investigação, pesquisa, descoberta, autonomia, sonhos e possibilidades, assim como o pensamento crítico e inovador. É uma proposta criada para estimular a liberdade de escolhas, através da qual cada instituição decidirá com sua comunidade o melhor caminho em busca da sustentabilidade (SATO; TRAJBER, 2010 apud BASTOS; RABINOVICI, 2016, p. 43).

Neste artigo, apresentaremos indicadores qualitativos enquanto instrumento de investigação do impacto efetivo das políticas públicas voltadas ao ensino e ao ambiente escolar. Estudos indicam estratégias metodológicas utilizadas para enfrentar o desafio de estabelecer indicadores qualitativos envolvendo políticas e avaliação do impacto de programas educacionais em escolas da educação básica (BAUER; SOUZA, 2015; ALVES; SOARES; XAVIER, 2014). Brito (2016) analisou esses indicadores qualitativos da influência da gestão participativa no desenvolvimento de projetos de cunho ambiental contemplados pelo PDDE Escolas Sustentáveis, no contexto da participação da União, via financiamento nos projetos idealizados pela comunidade escolar de quatro escolas do Município de Sobral (Estado do Ceará), escolhidas também pelo fato de o município constar entre as 25 melhores notas do Índice de Desenvolvimento da Educação Básica (IDEB) no ano de 2013, beneficiadas pelo programa citado, além das possibilidades que emergiram a partir da gestão conjunta desses recursos.

A conscientização ambiental nessas escolas foi tomada como indicador da eficácia dos projetos ambientais ali desenvolvidos. 
A concepção de indicador adotada aproxima-se da perspectiva de Minayo (2009, p. 85), na qual indicadores são instrumentos de análise que sugerem tendências, ou seja, não conseguem "aportar certeza absoluta quanto aos resultados de uma ação ou de um processo".

Na pesquisa desenvolvida por Brito (2016), é evidenciada a metodologia adotada para que sejam apresentadas maiores pistas do processo de pesquisa, dos resultados obtidos e de suas potencialidades. O processo metodológico (Figura 1) resultou na identificação dos indicadores qualitativos e permitiu visualizar a resposta da comunidade escolar frente aos projetos ambientais implantados, bem como na percepção de como ela assimilou e incorporou os aprendizados e desdobramentos possibilitados - dentre outras motivações - pelos recursos do PDDE - Escolas Sustentáveis.

Construir indicadores de pesquisa significa transformar conceitos e relações entre conceitos, que constituem as teorias com seus diferentes graus de generalidade e abstração, em categorias e proposições capazes de avançar na direção da explicitação das suas configurações e aplicações particulares.

Este estudo qualitativo enfatizou a natureza descritivo-analítica e utilizou a entrevista semiestruturada como instrumental técnico que possibilitou incorporar os significados, as intencionalidades e as significações presentes nos atos, relações e estruturas sociais das comunidades investigadas (BRITO; CUNHA; SÍVERES, 2018). Outras fontes de dados primários foram observações in loco registradas em notas de campo e análise documental. A observação facilitou a obtenção e a identificação de elementos concretos, legitimados pela espontaneidade na atuação dos participantes. Para a análise documental, foram pesquisados dados oficiais, resoluções do PDDE, projetos político-pedagógicos das escolas estudadas, e legislação referentes à educação ambiental, avaliados sob a luz da análise de conteúdo.

A formulação dos indicadores qualitativos compôs o ponto fundamental desses procedimentos, sistematizando a orientação para os resultados do estudo. Expressaram mais tangivelmente os resultados de uma adequada articulação entre a gestão, o fomento de projetos socioambientais pelo governo federal e o desenvolvimento sustentável nas escolas em estudo. Esses indicadores continham o significado dos dados gerados (BRITO; CUNHA; SÍVERES, 2018). A partir deles, a gestão participativa na esfera do financiamento de projetos socioambientais de escolas ajudou a gerar projetos educacionais voltados para o desenvolvimento sustentável (BRITO, 2016). 


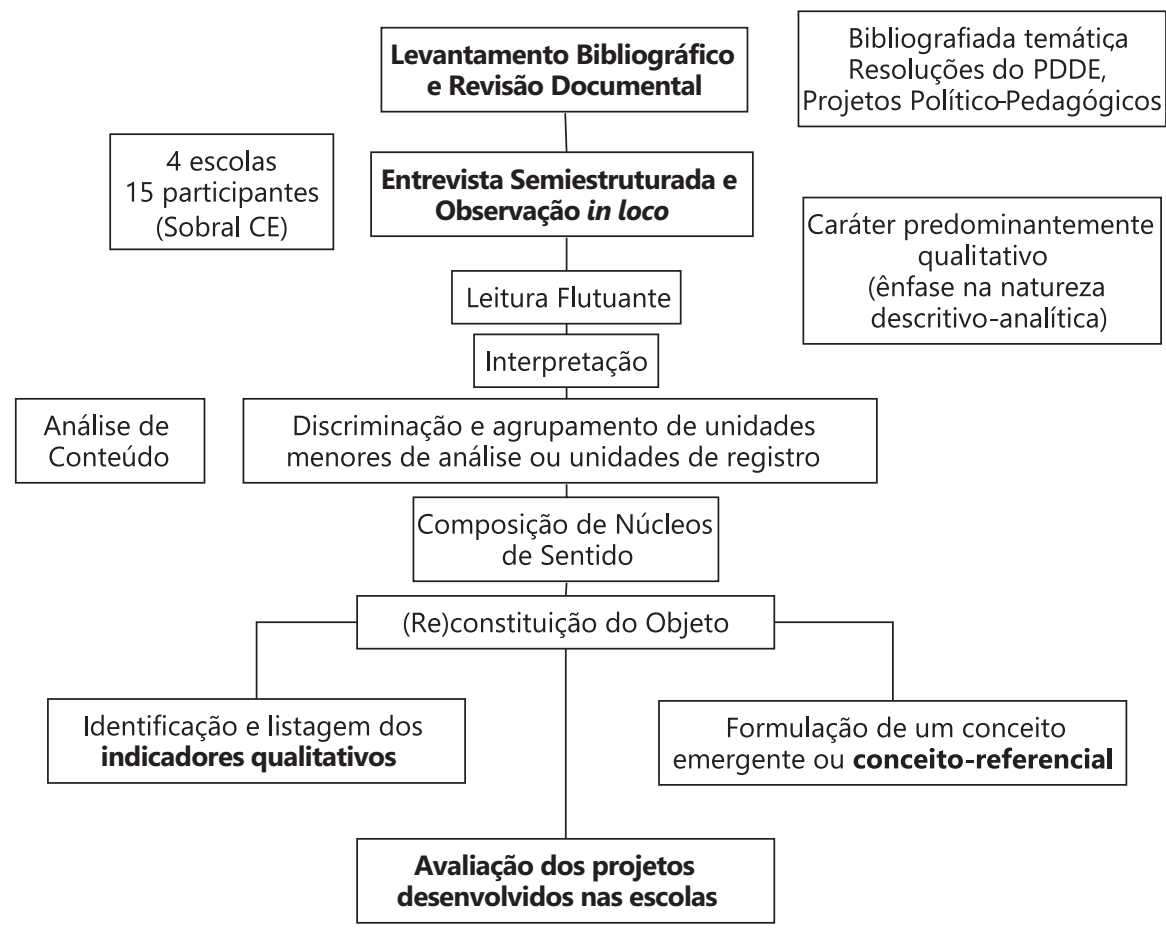

Fonte: Brito (2016)

Figura 1. Fluxograma da metodologia adotada

Os procedimentos próprios da análise de conteúdo mantiveram-se presentes na sistematização e na análise das informações, com o intuito de alcançar as categorias e os indicadores qualitativos. Essa técnica de análise contribuiu ao propor um conjunto de procedimentos de categorização, cujo objetivo consistiu na busca, tanto do entendimento da mensagem por meio da palavra verbalizada pelos participantes, como do sentido ou dos sentidos que pudessem emergir da mesma. As categorias foram construídas conforme os temas detectados no texto transcrito das entrevistas. Para classificar os elementos das falas em categorias, foram identificados os pontos em comum entre elas e realizados agrupamentos. Uma avaliação foi então iniciada no sentido de selecionar os documentos que demarcassem o corpus da análise e a elaboração dos indicadores que orientaram a interpretação e a preparação formal do material (BARDAN, 2011 apud BRITO; CUNHA; SÍVERES, 2018)

Os indicadores qualitativos elaborados manifestaram de maneira tangível os resultados da boa articulação entre a gestão participativa, o fomento de projetos socioambientais pelo Estado e o desenvolvimento sustentável nas 
escolas pesquisadas. Os indicadores foram constituídos a partir das categorias encontradas e permitiram atestar a efetividade da gestão participativa na execução de projetos educacionais voltados para o desenvolvimento sustentável (BRITO; CUNHA; SÍVERES, 2018). Essa foi a etapa mais importante dos procedimentos metodológicos e que permitiu o direcionamento para os resultados da pesquisa. $\mathrm{O}$ tratamento dos resultados da pesquisa foi feito a partir da interpretação de conceitos e proposições, bem como pela reflexão crítica do processo de pesquisa.

Foram obtidos dez indicadores ${ }^{1}$ extraídos pelos processos de categorização do material das entrevistas e pelo aporte bibliográfico sobre a temática. A partir deles, e da consideração teórico-empírica vivenciada pela pesquisa, um conceito emergente foi formulado ao encontro do próprio objetivo proposto pelo trabalho. Sua constituição foi respaldada na realidade empírica dos projetos de sustentabilidade socioambiental das escolas estudadas:

A sustentabilidade socioambiental, em escolas que adotam a gestão participativa, tem por princípio propiciar um sentimento de pertencimento, gerado pela convivência harmoniosa, baseada, por sua vez, na união de esforços e na qualificação de parcerias, para se ter acesso a materiais suficientes. Isto requer a descentralização da gestão, expressa na prática do aprendizado conjunto, preservando o envolvimento com o entorno, por intermédio das pequenas iniciativas, que, gradativamente, provocarão as grandes mudanças que trarão benefício mútuo para os segmentos da comunidade (BRITO, 2016, p. 126).

As conclusões obtidas consideraram as ações empíricas implantadas pelas escolas pesquisadas. O critério que determinou a escolha das escolas considerou o fato de terem sido contempladas pelo financiamento do PDDE - Escolas Sustentáveis. Esse critério foi adotado uma vez que foi reconhecida a falência do sistema educacional que, acrescida de outras motivações, caracteriza-se pelas escassas políticas públicas que distribuam recursos financeiros para a melhoria dos espaços físicos e dos materiais das escolas, o que poderia acarretar, diretamente ou indiretamente, na própria melhoria dos serviços que essas ofertam.

A proposição do conjunto de indicadores sobressaiu-se no estudo de Brito (2016), uma vez que apontam fatores que podem ser adotados como referência

Indicadores obtidos: pertencimento; união de esforços; qualificação de parcerias; descentralização da gestão; aprendizado conjunto; envolvimento com o entorno; convivência harmoniosa; pequenas iniciativas, grandes mudanças; benefício mútuo e acesso a materiais. 
de caracterização de certas situações ou contextos. Os indicadores surgiram da ação conjunta de importantes temáticas na área da Educação: sustentabilidade, gestão participativa e financiamento de projetos escolares socioambientais.

$\mathrm{Na}$ dimensão da sustentabilidade, faz-se necessário estabelecer espaços de diálogo para criar e executar ações que abranjam toda a comunidade escolar, tendo como objetivo final uma escola sustentável. Devem-se efetivar ações direcionadas à melhoria do meio ambiente e qualidade de vida, provocar uma maior interação entre a escola e toda a comunidade, uma vez que traz reflexos nas boas práticas sustentáveis. Uma educação voltada para a sustentabilidade expande o conhecimento e a consciência de gestores, discentes, educandos e comunidade escolar para atitudes e hábitos saudáveis.

Para a dimensão da gestão participativa, é indispensável que se tenha um maior estímulo para a comunidade na tomada de decisões, no trabalho coletivo, cooperativo e colaborativo do ambiente escolar. É preciso oferecer autonomia à comunidade, realizar reuniões de planejamento, convidando-a e socializando as propostas pedagógicas, convidando a comunidade para uma participação democrática nos espaços de decisão. A gestão democrática é o marco primeiro para a efetivação desses espaços sustentáveis, aberta ao diálogo e receptiva a uma comunidade participativa.

Em relação ao financiamento de projetos, faz-se necessária a liberação de recursos financeiros para as escolas públicas que apresentem propostas que envolvam a promoção da sustentabilidade socioambiental e que queiram se tornar espaços educadores sustentáveis com a participação de todos os envolvidos no espaço escolar e a comunidade em seu entorno.

A pesquisa evidenciou que os recursos obtidos pelo financiamento aumentaram a confiança e os esforços das comunidades, uma vez que tinham possibilidades de ações, até então restritas pelo aspecto econômico. Os impactos sociais também foram perceptíveis, especialmente na direção da melhoria da qualidade de vida da população que habita o entorno das escolas estudadas. Isso se deu pelo envolvimento com os projetos ambientais, que impactaram os envolvidos dentro e fora da sala de aula, de maneira profunda e contínua. Sobre o impacto ambiental, foi observado um crescimento na consciência dos moradores sobre a conservação, a preservação e o cuidado com o meio ambiente. Por fim, houve ainda um impacto institucional, na medida em que a escola criou bases potenciais para a realização de novos projetos que atendam à sustentabilidade socioambiental. 
Os processos participativos são itens fundamentais para a concretização da educação ambiental e para que surjam sociedades verdadeiramente sustentáveis. É fundamental que sejam avaliadas as ações desenvolvidas na escola, para que se compreenda a atual conjuntura e para que se possa deliberar de forma coletiva quais os cenários da sustentabilidade que se espera conseguir.

A fixação de escolas sustentáveis como espaços educadores torna-se indispensável para que se apresentem diálogos mais abertos com toda a comunidade escolar e o seu entorno. A formação continuada dos professores, gestores e alunos através de cursos, oficinas e eventos voltados para sustentabilidade ambiental é necessária para desenvolver habilidade e competências para a sustentabilidade almejada.

Os resultados do uso dos indicadores assinalados permitem que a situação socioambiental das escolas trabalhadas seja reconhecida, sendo fundamentais e imprescindíveis no sentido de uma reflexão de forma coletiva, na disposição, na preparação, no cumprimento, na direção do desenvolvimento dos trabalhos e na avaliação dos processos e conferição dos resultados alcançados. Ao mesmo tempo em que é capaz de se colocar em uma cooperação no significado de sugerir uma estrutura de gestão de políticas públicas, para examinar as características de cada indivíduo e os aspectos que não são de responsabilidade apenas da comunidade escolar, entretanto, sim, de todos, no caso de uma sociedade sustentável.

Um espaço educador sustentável só será possível quando acontecerem transformações em toda escola, desde a estrutura física, a gestão e a comunidade que fazem parte do projeto, produzindo conhecimentos e atitudes em relação à sustentabilidade ambiental. A gestão participativa deve promover ações ambientalmente sustentáveis como cursos de formação com supervisão e avaliação que envolvam comunidade, docentes e alunos, para proporcionar a mudança esperada.

A inclusão de espaços educadores sustentáveis apresenta inovações em relação à metodologias e conceitos concernentes à promoção da sustentabilidade. $\mathrm{O}$ estudo de Brito (2016) demonstrou que as escolas promoveram e efetivaram a implantação de espaços educadores sustentáveis, fazendo uma adaptação à infraestrutura e aos recursos humanos e pedagógicos.

Ao analisar a fixação dos espaços educadores sustentáveis por meio dos atores complementares desse contexto, afere-se que esse é um valioso instrumento metodológico e mediador do processo ensino-aprendizagem para promover a educação para a sustentabilidade. Para que exista uma real mudança, é necessário 
interferir no espaço e no contexto pedagógico, sensibilizar a comunidade escolar e dialogar, inserindo-a na tomada de decisões. Quando o trabalho é coletivo, direcionado a atingir uma meta, torna-se admissível a mudança de cultura e melhora na qualidade de vida socioambiental e a construção de uma comunidade sustentável.

\section{Considerações Finais}

A propagação de ideais de sustentabilidade e o fomento de projetos inseridos nessa temática caminham ao encontro da formação das chamadas escolas sustentáveis que, como formadoras de opinião e transformadoras de valores, têm um papel de extrema importância na sociedade em que se inserem. Faz-se necessário, porém, a consonância com todos, governo, gestores, professores, alunos, pais e sociedade em geral, pois sem essa ligação, muitas ações poderão não ser executadas ou mesmo se tornarem perdidas.

Estar preparado para agir e fazer os outros agirem de forma consciente é um processo que precisa ser trabalhado e levado a sério. Trabalhar de forma integrada e coesa é a forma mais ágil de se atingir o objetivo principal, que é o desenvolvimento da sustentabilidade e o respeito pelo meio ambiente, de forma a produzir um desenvolvimento socioambiental saudável, participativo e que acompanhe as mudanças de paradigmas culturais, sociais e tecnológicos no século XXI.

Podem-se avaliar aqui as potencialidades da imersão subjetiva proporcionada pelos indicadores qualitativos, em conjunto aos pressupostos da gestão participativa. Essas perspectivas acarretam, ainda, um processo reflexivo de todos os envolvidos, de modo que uma visão crítica pode ser constituída a partir da análise dos projetos e do cotidiano escolar. Não existiu preocupação em objetivar quantitativamente a subjetividade dessas percepções, por entender que elas expressaram o ponto de vista de cada participante. Todos atuam e vivenciam sobre aquela realidade, de modo que possuem propriedade para atestar os impactos exercidos pelos projetos socioambientais promovidos pelas escolas estudadas. Sob essa perspectiva, foram gerados indicadores de sustentabilidade socioambiental em escolas de gestão participativa.

Para incluir as questões ambientais no processo educativo, é preciso que a escola se articule com espaços não escolares. Dessa maneira, os alunos podem “(...) vivenciar experiências fora dos muros escolares e discuti-las em sala de aula. Com essa articulação, vislumbra-se a contextualização dos conteúdos e, consequentemente, o desenvolvimento do senso crítico e de atitudes participativas" (ARAÚJO; MODESTO; SANTOS, 2016, p. 135). A sustentabilidade na escola envolve ações individuais e coletivas. A educação ambiental não pode acontecer 
de maneira fragmentada, nem, tampouco, se voltar para coletivos genéricos, abstratos, fora dos contextos territorial e histórico (TRAJBER, 2011).

A respeito da relação entre educação e desenvolvimento sustentável, é necessário trabalhar também a interdisciplinaridade junto com o planejamento e o desenvolvimento dos sistemas educativos. Para isso, é necessária a interação e a ação geral dos atores locais no desenvolvimento da educação para o desenvolvimento sustentável, e também uma reforma curricular e estrutural no sistema educacional. É preciso que os formuladores e executores de políticas de educação tenham consciência de uma nova concepção de educação que inclua uma visão mais ampla do planeta, cujos recursos, fundamentais para a vida, precisam ser administrados com ética e responsabilidade coletiva e intergeracional.

A educação ambiental precisa assumir, ainda, dimensões de política pública, voltada para um futuro que tenha as escolas como referência, como espaços educadores para a sua comunidade. Ao cumprir esse papel estratégico das ações transformadoras, alerta que as ameaças, assim como as possibilidades de superálas, são também contemporâneas e apresentam desafios para as gerações presentes, não apenas para as futuras (TRAJBER, 2011).

A maneira de investigar a efetividade do uso de indicadores para avaliação qualitativa de projetos educativos socioambientais foi a formulação de indicadores para demonstrar como esse financiamento de projeto teve impacto. Foi uma pesquisa qualitativa e toda a geração de dados foi direcionada para essa abordagem, que analisou o discurso dos participantes em relação às mudanças experimentadas nas escolas.

A partir da bibliografia e da apreciação dos elementos que insurgiram da dimensão do estudo realizado em campo, as questões de sustentabilidade socioambiental nas escolas foram geradas de forma gradual, conscientizando toda a comunidade a observar o meio ambiente como um todo e não apenas na escala local. A comunidade entendeu a importância da responsabilidade e o compromisso com as outras pessoas em preservar o meio ambiente através de uma rede de cooperação, que foi desenvolvida pelos membros da escola, de parceiros e da comunidade. 


\title{
The use of indicators for qualitative evaluation of social environmental educational projects: participatory management in the school environment
}

\begin{abstract}
This article aims to discuss the new educational paradigms aimed at sustainable development in order to build a new school model from the most effective interaction of all those involved in the educational process, the families of students and society. This idea is based on the assumption of participatory management and is in line with the promotion of sustainability in the school environment to be considered as involving individual actions, but also as encompassing collective ones. Environmental education cannot be used as an action concerning only the individual in a fragmented way. Nor can it turn to generic, abstract collectives outside the territorial and historical context. This article also aims at discussing effectiveness of the use of qualitative indicators, in the sense of verifying if the results can be used in public policies directed to the school, as well as at discussing participatory management effectiveness in the constitution of sustainable schools.
\end{abstract}

Keywords: Sustainable Schools. Socio-environmental Development. Educational Paradigms. Participative Management.

\section{El uso de indicadores para evaluación cualitativa de proyectos educativos socioambientales: la gestión participativa en el medio ambiente escolar}

\section{Resumen}

Este artículo tiene como objetivo discutir los nuevos paradigmas educativos para el desarrollo sostenible a fin de construir un nuevo modelo de escuela, a partir de la interacción más eficaz de todos los involucrados en el proceso educativo, las familias de los alumnos y de la sociedad. Esta idea se basa en el presupuesto de la gestión participativa, y va al encuentro de la promoción de la sostenibilidad en el ambiente escolar al considerar que esa iniciativa involucra acciones individuales, pero también colectivas. La educación ambiental no puede reducirse a una actuación enfocada solo en el individuo, de manera fragmentada. Tampoco, puede volverse hacia colectivos genéricos, abstractos, fuera del contexto territorial e histórico. Este artículo apunta, además, a la discusión de la efectividad del uso de indicadores cualitativos, en el sentido de verificar si ellos pueden ser utilizados como balizadores de las políticas públicas dirigidas a la escuela, así como discutir la efectividad de la gestión participativa en la constitución de escuelas sostenibles.

Palabras clave: Escuelas Sostenibles. Desarrollo Social y Ambiental. Paradigmas Educativos. Gestión Participativa. 


\section{Referências}

ALVES, M. T. G.; SOARES, J. F.; XAVIER, F. P. Índice socioeconômico das escolas de educação básica brasileiras. Ensaio: Avaliação e Políticas Públicas em Educação, Rio de Janeiro, v. 22, n. 84, p. 671-704, jul./set. 2014. https://doi.org/10.1590/S0104-40362014000300005

ARAÚJO, M. I. O.; MODESTO, M. A.; SANTOS, T. F. Caminhos e dilemas da educação ambiental no contexto escolar. Pesquisa em Educação Ambiental, v. 11, n. 2, p. 129-36, 2016. https://doi.org/10.18675/2177-580X

BARCHI, R. Educação ambiental e (eco)governabilidade. Ciência \& Educação, Bauru, v. 22, n. 3, p. 635-50, 2016. https://doi.org/10.1590/1516-731320160030006

BASTOS, D. B. D.; RABINOVICI, A. A importância do processo de formação de educadores ambientais na efetividade do Programa Nacional de Escolas Sustentáveis - PNES. Revista Brasileira de Educação Ambiental, São Paulo, v. 11, n. 4, p. 42-59, 2016.

BAUER, A.; SOUSA, S. Z. Indicadores para avaliação de programas educacionais: desafios metodológicos. Ensaio: Avaliação e Políticas Públicas em Educação, Rio de Janeiro, v. 23, n. 86, p. 259-84, jan./mar. 2015. https://doi.org/10.1590/S0104-40362015000100010

BORGES, C. O que são espaços sustentáveis. Espaços Educadores Sustentáveis, v. 21, bol. 7, p. 111-6, jun. 2011.

BRASIL. Lei $\mathrm{N}^{\circ}$ 6.938, de 31 de agosto de 1981. Dispõe sobre a política nacional do meio ambiente, seus fins e mecanismos de formulação e aplicação, e dá outras providências. Diário Oficial da União, 2 set. 1981.

. Constituição da República Federativa do Brasil. Brasília, DF: Senado Federal, 1988.

. Lei N 9.795 de 27 de abril de 1999. Institui a Política Nacional de Educação Ambiental e da outras providências. Diário Oficial da União, 28 abr. 1999.

. Ministério do Meio Ambiente. Programa Nacional de Educação Ambiental - ProNEA. 3a ed. Brasília, DF, 2005. 
BRITO, R. O. Gestão participativa e sustentabilidade socioambiental: um estudo em escolas da rede pública de Sobral-CE. 2016. 192 f. Tese (Doutorado em Educação) - Universidade Católica de Brasília, Brasília, DF, 2016.

BRITO, R. O.; CUNHA, C.; SÍVERES, L. Gestão participativa e sustentabilidade socioambiental: um estudo em escolas da rede pública de Sobral-CE. Ciência \& Educação, Bauru, v. 24, n. 2, p. 395-410, 2018. https://doi.org/10.1590/1516-731320180020009

CATALISA - Rede de Cooperação para a Sustentabilidade. Relatório BrundHand. Belo Horizonte; 2005. Disponível em: $<$ https://catalisa.org.br/ catalisando/educacao-ambiental/relatoriobrundtland >. Acesso em: 7 jul. 2018.

GADOTTI, M. Educar para a sustentabilidade: uma contribuição à década da educação para o desenvolvimento sustentável. São Paulo, SP: Instituto Paulo Freire, 2008. (Série Unifreire)

LEFF, E. Saber ambiental: sustentabilidade, racionalidade, complexidade, poder. Rio de Janeiro, RJ: Vozes, 2001.

MINAYO, M. C. S. Construção de indicadores qualitativos para avaliação de mudanças. Revista Brasileira de Educação Médica, v. 33, s. 1, p. 83-91, 2009. https://doi.org/10.1590/S0100-55022009000500009

MOREIRA, T. Escola sustentável: currículo, gestão e edificação. Espaços Educadores Sustentáveis, v. 21, bol. 7, p. 17-22, jun. 2011.

NEWTON, A. P. B. et al. Educação e conhecimento para um futuro sustentável. São Paulo, SP: Alínea, 2011.

NOVICKI, V. Educação para o desenvolvimento sustentável ou sociedades sustentáveis? Linhas Críticas, Brasília, v. 14, n. 27, p. 215-32, jul./dez. 2009.

PADILHA, P. R. Uma escola mais bela, alegre e prazerosa. In: GADOTTI, M.; GOMEZ, M. V.; FREIRE, L. Lecciones de Paulo Freire, cruzando fronteras: experiencias que se completan. Buenos Aires: CLACSO, 2003. p. 83-92.

PAULA, J. Uma agenda para o Brasil: uma agenda de desenvolvimento humano e sustentável para o Brasil do século XXI, PNUD. Brasília, DF: Millenium/Instituto de Política, 2000.

REZENDE; T. F.; SILVA, G. F. da. A relação família-escola na legislação educacional brasileira (1988-2014). Ensaio: Avaliação e Políticas Públicas 
em Educação, Rio de Janeiro, v. 24, n. 90, p. 30-58, jan./mar. 2016. https://doi.org/10.1590/S0104-40362016000100002.

RUSCHEINSKY, A. et al. Educação ambiental: abordagens múltiplas. 2a ed. Porto Alegre: Penso, 2012.

SÍVERES, L. Sustentabilidade educacional. Revista de Educação ANEC, Brasília, DF, n. 152, p. 45-57, 2010.

TRAJBER, R. Vida sustentável: ações individuais e coletivas Espaços Educadores Sustentáveis, v. 21, bol. 7, p. 22*9, jun. 2011.

UNESCO. Década da educação das Nações Unidas para um desenvolvimento sustentável, 2005-2014: documento final do esquema internacional de implementação. Brasília, DF, 2005.

. Declaração de Incheon: educação 2030: rumo a uma educação de qualidade inclusiva e equitativa e à educação ao longo da vida para todos. In: FÓRUM MUNDIAL DE EDUCAÇÃO, 2015, Incheon. Relatório... Genebra, 2015.

\section{Informações dos autores}

Renato de Oliveira Brito: Doutor em Educação. Docente e Pesquisador Permanente do Mestrado e Doutorado em Educação da Universidade Católica de Brasília. Contato: e-mail: renatoorios@gmail.com.

iD https://orcid.org/0000-0002-9345-2529

Luíz Siveres: Doutor em Desenvolvimento Sustentável. Coordenador, Docente e Pesquisador Permanente do Mestrado e Doutorado em Educação da Universidade Católica de Brasília. Contato: e-mail: luiz.siveres@catolica.edu.br.

iD https://orcid.org/0000-0003-4735-6066

Célio da Cunha: Doutor em Educação. Docente e Pesquisador Permanente do Mestrado e Doutorado em Educação da Universidade Católica de Brasília. Contato e-mail: celio. cunha226@gmail.com

(iD) https://orcid.org/0000-0002-9212-4208 